\title{
A linguagem do futebol no ENSINO De ITALIANO: ANÁLISE DE LIVROS DIDÁTICOS E PROPOSTA DE GLOSSÁRIO
}

\author{
Il linguaggio del calcio nell'insegnamento \\ dell'italiano: analisi di libri didattici e proposta di \\ glossario
}

\section{The Language of Football in the Teaching of Italian: An Analysis of Textbooks and a Glossary Model}

\author{
Beatriz Anastacia Dállia Martins* \\ Angela Maria Tenório Zucchi* *
}

RESUMO: O futebol é um dos esportes mais praticados no mundo e os termos relativos a ele estão presentes nos livros didáticos em italiano como língua estrangeira. Este trabalho tem como objetivo apresentar parte da pesquisa realizada para a elaboração de um glossário de termos do futebol em italiano para fins didáticos. Inicialmente, contextualiza o tema, relacionando a importância desse esporte para brasileiros e italianos, na sequência apresenta o aporte teórico de estudos em Lexicografia, Terminologia, Fraseologia e didática de línguas estrangeiras, a partir de Aubert (2001), Autelli (2015), Balboni (1994, 1998), Bevilacqua (1998, 2005), Biderman (2001), Krieger (2004), Tagnin (2013), Zucchi (2010), entre outros, além de estudos sobre a linguagem do futebol (GALLI, 2011; MATTOS, 2002; QUEIROZ, 2005) e, enfim, apresenta a metodologia empregada e parte dos resultados. Foram selecionados dezoito livros didáticos de italiano como língua estrangeira elaborados e editados na Itália entre os anos de 1998 e 2018. A partir desse corpus, foram identificadas as ocorrências de termos e fraseologismos relacionados com o universo futebolístico em unidades didáticas totalmente dedicadas a esse esporte ou em textos e exercícios relativos a esporte ou lazer. A análise resultou em 451 diferentes registros de termos e fraseologismos que formaram a nomenclatura do glossário. Neste artigo, apresentamos a metodologia empregada e uma amostra do glossário.

PALAVRAS-CHAVE: Italiano; Futebol; Lexicografia; Fraseologia; Ensino de LE.

\footnotetext{
* Mestre em Língua, Literatura e Cultura Italianas - Universidade de São Paulo

prof.beatrizdallia@gmail.com (ORCID: 0000-0003-2019-540X)

** Docente - Universidade de São Paulo

angelazucchi@usp.br (ORCID: 0000-0001-5464-5742)

DOI: http://dx.doi.org/10.11606/issn.2238-8281.v0i42p132-157
} 
ABSTRACT: Il calcio è uno degli sport più praticati al mondo e i termini ad esso correlati sono presenti nei manuali didattici in italiano come lingua straniera. Questo lavoro si propone di presentare la metodologia e i risultati per l'elaborazione di un glossario di termini calcistici in italiano a scopo didattico. Inizialmente, contestualizza il tema, mettendo in relazione l'importanza di questo sport ai brasiliani e agli italiani e in seguito presenta il contributo teorico di studi in Lessicografia, Terminologia, Fraseologia e didattica delle lingue straniere, a partire da Aubert (2001), Autelli (2015), Balboni (1994, 1998), Bevilacqua (1998, 2005), Biderman (2001), Krieger (2004), Tagnin (2013), Zucchi (2010), tra gli altri, oltre a studi sul linguaggio del calcio (GALLI, 2011; MATTOS, 2002; QUEIROZ, 2005) e, infine, presenta la metodologia utilizzata e parte dei risultati. Sono stati selezionati diciotto libri didattici dell'italiano come lingua straniera e che sono stati pubblicati in Italia tra il 1998 e il 2018. Da questo corpus, sono stati individuati termini ed espressioni legati all'universo del calcio in unità didattiche totalmente dedicate a questo sport o in testi ed esercizi legati allo sport o al tempo libero. L'analisi ha prodotto 451 registrazioni di termini e fraseologismi che hanno formato la nomenclatura del glossario. In questo articolo presentiamo la metodologia utilizzata e un saggio del glossario.

PAROLE CHIAVE: Italiano; Calcio; Lessicografia; Fraseologia; Insegnamento di LS.

ABSTRACT: Football is one of the most popular sports in the world and the terms related to it are present in textbooks of Italian as a foreign language. This work focuses on part of a study conducted to create a glossary of football terminology in Italian with didactic purposes. At first, we contextualize the theme of this paper by discussing the importance of the aforementioned sport to Brazilians and Italians. After, we present our theoretical foundation, which relies on works in the field of Lexicography, Terminology, Terminography, Phraseology and Foreign Language Teaching in consonance with scholars such as Aubert (2001), Autelli (2015), Balboni (1994, 1998), Bevilacqua (1998, 2005), Biderman (2001), Krieger (2004), Tagnin (2013), Zucchi (2010), and on research on the language of football (GALLI, 2011; MATTOS, 2002; QUEIROZ, 2005). Finally, we demonstrate the methodology applied and part of the results. Eighteen textbooks of Italian as a foreign language were selected, all of which were produced and edited in Italy between 1998 and 2018. Within this corpus, we identified the occurrences of terms and phraseologies related to the football universe in didactic units which were entirely dedicated to this sport or in texts and exercises related to sports and recreation. The analysis retrieved 451 occurrences of terms and phraseologies that constitute the glossary. In this paper, we present the methodology applied and a sample of the glossary.

KEYWORDS: Italian; Football; Lexicography; Phraseology; Foreign Language Teaching. 


\section{Introdução}

A pesquisa que apresentamos traz destaque à linguagem do futebol (doravante LF) no ensino de língua estrangeira ao propor um glossário sobre esse tema a aprendizes brasileiros de italiano como língua estrangeira (doravante LE). A proposta do glossário é o resultado do levantamento e análise de termos e fraseologismos sobre futebol em livros didáticos e visa a oferecer um subsídio para o ensino de italiano.

O livro didático, em italiano manuale didattico, é o material que conduz a maioria dos cursos de italiano no Brasil. A decisão editorial sobre a escolha dos temas que são incluídos em um livro didático determina o conjunto vocabular a ser ensinado e aprendido em um curso. A presença da LF nos livros didáticos demonstra a importância desse vocabulário para os aprendizes de italiano, uma vez que o futebol, il calcio, faz parte da cultura italiana.

Seguir ou não um livro didático pode trazer algumas implicações, como aponta Frangiotti (2019) em seu estudo ${ }^{1}$ sobre esse material do ponto de vista sociolinguístico. Na prática, percebemos que na maioria das vezes ele é o guia para alunos e professores adentrarem no universo linguístico e cultural do país estrangeiro.

Em relação a temas específicos da cultura, e socialmente significativos como o futebol, o aprendizado pode ficar limitado a um texto ou a um exercício apresentado pelo livro onde são introduzidos alguns dos termos. Caberá ao professor e ao aluno buscar material complementar conforme seus interesses e necessidades.

Este estudo procurou, de um lado, fornecer um material de apoio para o ensino e, de outro, averiguar quanto e de que forma estão presentes os termos e os fraseologismos relativos à LF nos livros didáticos de italiano. Para esse fim, fundamentamo-nos no referencial teórico dos estudos em Lexicologia, Lexicografia, Terminologia e Fraseologia (ALMEIDA, 2003; AUBERT, 2001; BEVILACQUA, 1998, 2005; BIDERMAN, 2001; KRIEGER; FINATTO, 2004; TAGNIN, 1998, 2013; ZUCCHI, 2010) e didática em LE (AUTELLI, 2015; BALBONI, 1994, 1998, 2008, entre outros), além de estudos sobre a LF (GALLI, 2011; MATTOS, 2002; QUEIROZ, 2005, entre outros). A metodologia empregada para esse fim será apresentada ao longo deste artigo.

\section{Futebol: cultura, sociedades, fatos históricos e ensino de línguas estrangeiras (LE)}

O envolvimento de uma nação com os esportes é também um fator cultural. O futebol é um dos esportes mais praticados no mundo e, quando o assunto é bola na rede, Brasil e Itália são

1 Frangiotti (2019, p.17-38) cita a pesquisa de Coracini (1999) sobre o emprego do livro didático por professores de LE, que identificou duas tendências: uso fiel ou abandono completo. Na primeira, o livro aparece como 'modelo a ser seguido'. Em sua pesquisa, Frangiotti analisa dois livros didáticos a partir da dimensão diastrática, ou seja, a variação que inclui traços linguísticos relativos às características sociais, e conclui que essa variedade é pouco presente e que a abordagem a ela é preconceituosa. 
rivais, mas acima de tudo, são países onde as pessoas amam acompanhar as competições, além de serem nações que conquistaram expressivo número de títulos mundiais. O Brasil venceu cinco Copas do Mundo (1958, 1962, 1970, 1994 e 2002), já a Itália venceu quatro vezes (1934, 1938, 1982 e 2006). Observando essas conquistas mundiais bastante próximas, consideramos que esse esporte é de interesse da população dos dois países e que, portanto, um estudo didático-linguístico, que tem como público-alvo aprendizes brasileiros, contribui para o ensino do italiano como LE.

Os recortes dados ao futebol pelos livros de italiano LE são variados, pois falar sobre essa prática esportiva faz parte da cultura dos italianos desde o século XV, quando os nobres florentinos praticavam o esporte nas grandes praças de Florença².

No entanto, o futebol não é somente o esporte de preferência dos italianos como prática esportiva profissional, mas um passatempo que gera discussões profundas sobre o assunto, uma vez que há canais de televisão ${ }^{3}$ destinados apenas a falar sobre ele, como RAI sport, Mediaset e TV8.

Compreender essa linguagem de especialidade nos coloca como conhecedores de um aspecto importante da cultura desse povo. Como afirma Aubert (2001), a “(...) linguagem de especialidade é o conjunto de marcas lexicais, sintáticas, estilísticas e discursivas que tipificam o uso de um código linguístico qualquer em ambiente de interação social centrado em uma determinada atividade humana" (p. 25).

Partindo dessa afirmação, podemos dizer que estudar o léxico especializado nos coloca em condição de uma interação social mais proveitosa, auxiliando a comunicação entre profissionais de uma mesma área e falantes de um mesmo idioma, seja como língua materna ou como língua estrangeira.

Entendemos que ensinar essa forma tão singular de se expressar não significa apenas fazer um pequeno recorte dentre tantos outros assuntos que poderiam ser abordados, mas é colocar o aprendiz na condição de falante em um grau mais específico da língua e inseri-lo dentro da cultura daquele povo. Este trabalho objetiva auxiliar aprendizes e professores de italiano na comunicação nessa área de especialidade, visto que o glossário da terminologia de futebol é um auxílio àqueles que se interessam, fazem ou queiram fazer uso dessa linguagem.

Apresentamos brevemente alguns fatos históricos relativos a esse esporte. O futebol é um esporte praticado há mais de 2000 anos, ou seja, o amor por ele é antigo, atravessou o tempo e, sem dúvida, civilizações e gerações. Não é possível precisar a origem do futebol, como o conhecemos hoje, mas estudos indicam que tenha começado oficialmente na Inglaterra em 1863, quando o país fundou a Football Association e arquitetou as regras, sendo ainda conservada boa parte delas nos dias atuais (MATTOS, 2002).

2 Cf. Calcio storico fiorentino em https://cultura.comune.fi.it/calcio-storico-fiorentino e https://www.intersport.it/get-inspired/calcio-storico-fiorentino-storia-regole

3 Cf. Calcio in televisione in Italia: https://it.wikipedia.org/wiki/Calcio_in_televisione_in_Italia 
O esporte, no entanto, já era praticado no período de expansão do Império Romano, concorrendo, naquela época, com os esportes individuais como arco e flecha, lança, dentre outros (QUEIROZ, 2005). Na península itálica, um esporte semelhante era praticado na cidade de Florença durante o período medieval. Segundo Fernandes:

Durante a Idade Média, surge na Itália, sob o nome de gioco del calcio, uma modalidade de futebol jogada por duas equipes, cada uma com 27 jogadores, geralmente nobres, praticado obrigatoriamente em uma praça de Florença, e cujo objetivo era conduzir uma bola recoberta com couro até dois postes de madeira, localizados na extremidade da praça. Há registro de grande violência na prática desse esporte. (FERNANDES, 1974, apud QUEIROZ, 2005, p. 30)

Há outros registros da origem do futebol datados antes da Idade Média. Galli (2011) traz a informação de que, na China, o esporte era praticado pelos soldados durante a dinastia Zhou (1045-256 antes de Cristo). O jogo se chamava Ts'uh-chüh, em que Ts'uh significa "golpear com os pés" e chüh "bola".

O futebol no Brasil deve muito ao paulistano Charles Miller, por trazer o esporte e suas regras ao país. Já na Itália, ele chegou através de Edoardo Bosio, um funcionário (também atleta de canoagem pela Società Armida) de uma empresa britânica em Turim que, devido ao seu contato com os ingleses, convenceu seus colegas a praticar o jogo e fundou o primeiro time de futebol na Itália, em Turim, em 1887, o Torino Football and Cricket Club, segundo o Arquivo Histórico do Município de Turim ${ }^{4}$.

Esses fatos históricos sobre o futebol nos levam a pensar que em ensino de línguas estrangeiras - considerando a definição de LE de Balboni (1994, p. 14), isto é, não estando o aprendiz no país de origem da língua que está aprendendo - torna-se impossível ensinar língua sem que se faça uma abordagem da cultura daquele país.

A língua, expressão do patrimônio cultural de um povo, deve ser entendida como um sistema aberto que é construído e modificado por seus falantes. Por sua vez, estes podem mudar, ou não, a forma de se expressar num determinado período, variando o repertório linguístico de acordo com a comunidade ou o meio profissional em que estejam inseridos, ideia que vemos em Antunes (2009):

Efetivamente, a língua, sob a forma de uma entidade concreta, não existe. O que existe são falantes; são grupos de falantes. A língua, tomada em si mesma, não passa de uma abstração, de uma possibilidade, de uma hipótese. O que existe de concreto, de observável são os falantes, que, sempre, numa situação social particular, usam, (e criam!) os recursos linguísticos para interagirem uns com os outros e fazerem circular a gama de valores culturais que marcam cada lugar, cada situação e cada tempo. (p. 22)

4 Comune di Torino, Archivio Storico, 2005: http://comune.torino.it/archiviostorico/mostre/sport_2005/ pdf/085-096.pdf; Canottieri Armida: http://www.canottieriarmida.it/index.php/news/73-19032008-maggio-1898-2008-centodieci-anni-del-primo-campionato-di-calcio-italiano 
A forma como nos comunicamos nada mais é do que a nossa identidade, e a maneira como nos relacionamos nos espaços em que vivemos diz muito acerca das nossas escolhas linguísticas. Embora saibamos utilizar o mesmo código, ou seja, a língua, nos diferenciamos em nossas escolhas quando queremos nos expressar. Logo, "cai por terra" o conceito de certo ou errado quando o assunto é se fazer entender. Quando aprendemos a língua do outro e buscamos compreender esse novo idioma, nos tornamos sujeitos plurais, agregando novos conceitos e culturas e passando a fazer pequenas comparações entre a nova língua e a nossa materna, a fim de verificar as semelhanças e as diferenças que esse tecido cultural tem a nos oferecer.

Língua e cultura são indissociáveis, uma vez que uma se alimenta da outra, criando um único DNA, porque são portadoras das experiências de nossos antepassados e, sem dúvida, porque nos acompanham por toda a nossa vida.

Ensinar novos idiomas vai além do uso correto da gramática, é estar atento às diferenças culturais e como esses fenômenos podem ser determinantes para uma melhor comunicação, independentemente do nível em que esteja inserido o aprendiz.

Portanto, concluímos que língua e cultura percorrem a mesma trajetória na comunicação e que não há como excluir do processo de aprendizagem essa combinação entre língua e cultura, posto que essa união apoia o desenvolvimento do aluno para alcançar um determinado nível de enriquecimento vocabular em várias esferas de uma LE.

\section{A contribuição das Ciências do Léxico para o ensino de LE}

Aprendizes de LE geralmente se preocupam em adquirir novos vocábulos no início do aprendizado, mas a tarefa não é fácil, pois para essa aquisição é necessário compreender que o processo requer tempo, estudo e, claro, o uso da língua, para que se coloque em prática todos os novos termos adquiridos.

Em se tratando de aquisição de novas palavras, podemos recorrer às Ciências do Léxico 5 como uma aliada tanto para o aprendizado quanto para o entendimento sobre quando utilizá-las. Neste trabalho, nosso foco está nas seguintes áreas: Lexicologia, Lexicografia, Terminologia, Terminografia, Fraseologia.

A Lexicologia é a ciência que se ocupa da análise da palavra. Segundo Biderman (2001), “(...) A Lexicologia, ciência antiga, tem como objeto básico de estudo e análise a palavra, a categorização lexical e a estruturação do léxico" (p. 16). Com palavras, um povo nomeia o mundo ao seu redor e representa sua cultura, suas crenças e seus costumes. A Lexicologia trata das palavras no âmbito do que é considerado léxico comum ou léxico geral, ao passo que a Terminologia se ocupa da palavra enquanto "termo" num determinado discurso, no âmbito de uma linguagem de especialidade, que possui um léxico relativo a um determinado tema. Krieger e Finatto (2004) esclarecem que

$5 \quad$ Vale ressaltar que no Brasil há reconhecida tradição em nomear "Ciências do Léxico", enquanto em outros países se usa "Estudos do Léxico" (Lexical Studies). Cf. A coleção de livros "Ciências do Léxico" em http://www. letras.ufmg.br/padrao_cms/?web=gtlex\&lang=1\&page=2326\&menu=1544\&tipo=1 
O léxico temático configura-se, portanto, como um componente linguístico, não apenas inerente, mas também a serviço de comunicações especializadas, posto que os termos transmitem conteúdos próprios de cada área. Por isso, os termos realizam duas funções essenciais: a de representação e a de transmissão do conhecimento especializado. (p. 17)

Apesar de termos técnico-científicos serem utilizados há tempos, “(...) os estudos terminológicos são recentes e a Terminologia passou a ser vista como campo de estudos apenas na segunda metade do século XX" (KRIEGER; FINATTO, 2004, p. 25). O desenvolvimento desses estudos deu-se pelo desejo do engenheiro austríaco Eugen Wüster - que deu origem à Teoria Geral da Terminologia (TGT) - de normalização dos termos em busca de uma comunicação inequívoca e estandardizada dentro de uma área técnica específica. Dada a insuficiência desta teoria em relação às características pragmáticas da comunicação real, seu lugar foi ocupado pela Teoria Comunicativa da Terminologia (TCT), elaborada pela linguista e filóloga catalã Maria Teresa Cabré ao longo dos anos 1990. A TCT aborda o termo em toda sua complexidade, como unidade de um sistema linguístico dinâmico, e considera as perspectivas social, cognitiva e linguística para o estudo dos "objetos terminológicos (conhecimento especializado, textos especializados e unidades terminológicas)", segundo Almeida (2003, p. 214-216).

A LF é constituída pelo conhecimento especializado dentro da realização desse esporte, por termos e unidades terminológicas que designam tanto ações dentro do campo como fora dele. As posições dos jogadores (goleiro, centroavante, lateral), as sanções disciplinares (cartão amarelo, cartão vermelho) são termos específicos dessa área. Na comunicação entre falantes de um determinado idioma sobre "futebol", surge o emprego de termos, mas também de expressões idiomáticas, de expressões fixas e até de provérbios.

Nas Ciências do Léxico, a área que estuda as expressões, locuções, combinações de palavras cristalizadas pelo uso é a Fraseologia. Sob a ótica dos estudos fraseológicos, poderíamos discorrer sobre várias manifestações linguísticas, porém, neste artigo, vamos nos ater às formações lexicais e nomenclaturas de interesse desta pesquisa.

No âmbito de uma língua de especialidade, os estudos fraseológicos recebem o nome de Fraseologia Especializada. Bevilacqua (1998) cunha o termo "unidade fraseológica especializada" (UFE) e o define:

unidades sintagmáticas de significação especializada que incluem um elemento eventivo (verbal ou procedente de verbo) e, no mínimo, uma unidade terminológica. Além disso, possuem certo grau de fixação, determinado mais pela relação semântica estabelecida entre os elementos que as compõem que pelas relações sintáticas, e uma frequência relevante em determinado âmbito ou nos textos especializados em que são utilizadas. (p. 1)

A autora oferece exemplos na área de direito ambiental: "instaurar inquérito", "captação de energia", que são UFEs em que há um termo (inquérito, energia) e um elemento eventivo caracterizado pelo verbo (instaurar) ou por substantivo deverbal (captação). Na LF, podemos 
exemplificar com "marcar um gol", "cometer uma falta", "chute a gol", em que os termos são "gol" e "falta" combinados com verbos (marcar, cometer) e substantivo deverbal (chute). Bevilacqua (1998, p. 2) adverte sobre a diferença entre a UFE e a "unidade terminológica poliléxica" (UTP), indicando que esta última possui um caráter denominativo e referencial, dando como exemplo "energia nuclear" e "energia eólica". Em relação ao futebol, temos "tiro livre", "ala esquerda" ou "ala direita".

As combinações de palavras comuns recebem também outra nomenclatura por estudiosos que as entendem como "colocações", classificadas segundo sua formação morfológica. Tagnin (1998, p. 41) propôs uma definição para colocação: "Uma colocação é uma combinação lexical recorrente, não-idiomática, coesa, cujos constituintes são contextualmente restritos e de co-ocorrência arbitrária”. A autora apresenta uma categorização a partir dos elementos composicionais: colocações adjetivas Adj + S (Feliz Natal, Merry Christmas), colocações nominais (instrumento de tortura, torture device), colocações verbais (marcar um encontro, make a date), colocações adverbiais (gravemente ferido, critically injured) (TAGNIN, 2013, p. 64-73) ${ }^{6}$.

Outros autores preferem não especificar as diferenças entre as combinações, como demonstramos até aqui, e simplesmente adotam o termo "fraseologismo", como afirma Blais (1993):

Entre a grande quantidade de nomes, frequentemente mal definidos, para designar essa extensão sintagmática do termo para a frase (locução terminológica, locução fraseológica, co-ocorrente, colocação, expressão idiomática etc.), nós adotamos o termo fraseologismo, já utilizado por alguns autores (Picht, Cormier), pois trata-se de fraseologia de língua de especialidade, isto é, de um fenômeno sintático relacionado a "um sistema de particularidades expressivas ligadas às condições sociais nas quais a língua se atualiza”. (p. 51)

Independentemente da denominação adotada, o entendimento de que uma sequência de palavras fixa e recorrente no uso forma uma "unidade com significado" é importante para o ensino e aprendizado de LE e para a tradução, pois nem sempre as sequências se constituem da mesma maneira em duas línguas e tampouco são necessariamente correspondentes. Quando compreendido um fraseologismo e, por consequência bem empregado, seu uso coloca o falante em um grau mais avançado de conhecimento da língua. O estudo da Fraseologia é, portanto, valioso para o ensino e aprendizado de um idioma e para quem se interessa por tradução, como também pelas áreas especializadas, como é o caso da LF, que tem uma linguagem própria e técnica.

$6 \quad$ Na edição de 2013 são apresentados também exemplos em alemão, espanhol, francês e italiano.

$7 \quad$ No original: Parmi extrême profusion d'appellations souvent mal définies pour désigner cette extension syntagmatique du terme à la phrase (locution terminologique, locution phraséologique, coocurrent, collocation, expression idiomatique, etc.), nous avons retenu le terme phaséologisme, déjà utilisé par certains auteurs (Picht, Cormier), parce qu'il s'agit bien de phraséologie de langue de spécialité; est-à-dire d'un phénomène syntaxique relié à « un système de particularités expressives liées aux conditions sociales dans lesquelles la langue est actualisée » (tradução para o português de Renata Tonini Bastianello) 
Quando trabalhamos com língua de especialidade é importante salientar a importância da Lexicografia e da Terminografia. Ambas se ocupam de obras com características de dicionários, sendo que, se for de língua geral e comum, é uma obra lexicográfica e, se for de uma área específica, é considerada uma obra terminográfica, porque tratará de termos.

A Terminografia objetiva a compilação de termos para a produção de glossários, dicionários técnicos e bancos de dados terminológicos. A compilação de um léxico especializado serve para um melhor entendimento na comunicação entre as pessoas envolvidas na área e para a difusão desse conhecimento, auxiliando também nas traduções técnicas.

Os dicionários são instrumentos importantes para o ensino e aprendizagem de uma LE, ajudando o aprendiz de LE a ampliar seu vocabulário e, de certo modo, dando-lhe liberdade para se desenvolver nas competências básicas do aprendizado de uma segunda língua, como a escrita e a fala. Zucchi (2010) afirma que:

Com a devida orientação, o dicionário constitui um importante instrumento para a autonomia do aprendiz de LE. Não há de se esquecer, todavia, que é necessário subsidiar o aluno a se informar sobre o dicionário: que tipo de obra é, qual o público a que se destina e como se organiza sua macro e microestrutura. (p. 256)

Pensando na disposição das informações em um dicionário, para definir a organização geral da obra utilizamos o termo "macroestrutura", que pode ser semasiológica (apresentação em ordem alfabética) ou onomasiológica (ordem conceitual, por temas). Para fazer referência à organização do conteúdo dos verbetes, o termo empregado é microestrutura ${ }^{8}$.

Os dicionários têm uma grande importância pedagógica, podendo ser utilizadas obras de diversos tipos no ensino de idiomas: de língua geral, eletrônico, híbrido, impresso, visual, multilíngue, bilíngue, monolíngue, pedagógico, especializado, entre outros. Neste trabalho, procuramos seguir o modelo tradicional de dicionários monolíngues, com organização semasiológica e com informação morfológica das entradas.

O uso dos dicionários como um instrumento de aprendizagem é necessário, inclusive nas primeiras séries escolares, ou seja, quando o aluno começa a escrever e a entender o mundo que o circunda. Algo semelhante ocorre com o aprendiz de LE, pois diversos livros didáticos sugerem aos alunos iniciantes que escrevam redações curtas com o propósito de colocar em prática o léxico assimilado. Esse exercício pode ser solicitado para que o aluno desenvolva o léxico adquirido após ter estudado uma determinada unidade do livro e, por vezes, sendo seu repertório lexical ainda insuficiente, o estudante busca dicionários para o orientar no processo de escrita. Acreditamos que esse seja um momento precioso para o professor, posto que ele pode estimular ainda mais o aprendiz na descoberta de novas palavras. Ensiná-lo a procurá-las pode ser benéfico para que ele aumente sua capacidade de ampliar o léxico e possa se expres-

$8 \quad$ Os termos macroestrutura e microestrutura, e seus respectivos conceitos, foram introduzidos por R. Rey Debove em 1971 e adotados por todos os estudiosos de Lexicografia (WELKER, H.A, Dicionários - uma pequena introdução a Lexicografia, 2004). 
sar com mais argumentos a respeito de um determinado assunto, não apenas no processo de desenvolvimento da escrita, mas também no da fala. A prática do uso de dicionários deve ser estimulada em todos os níveis como um apoio constante para o alcance do sucesso pleno de se comunicar em um novo idioma.

No processo de ensino e aprendizagem de uma LE há muitos recursos disponíveis. O livro didático é o recurso que guia a maioria dos cursos de línguas e contribui para facilitar a aquisição do novo idioma. O livro, formado por textos, é o instrumento de trabalho do professor, e este tem a liberdade de se debruçar com mais atenção sobre os elementos que compõem tais textos, dando mais relevância às estruturas linguísticas, gramaticais ou semânticas, e ao conteúdo cultural que apresentam. Autelli (2015) considera que

Para um professor, refletir sobre o ensino de uma língua significa raciocinar de maneira focada e detalhada sobre a natureza de determinados aspectos linguísticos, suas características e seu comportamento no interior de um discurso ou de um texto. (p. 179) ${ }^{9}$

A seleção e a organização do material didático no ensino de LE frequentemente não cabem ao professor, mas o mesmo não se pode dizer sobre a escolha do tempo a ser dedicado a cada tema. Não se pode descartar as peculiaridades que cada texto traz, pois, numa aula, o tratamento dado ao discurso pelos seus integrantes toma por si só caminhos independentes. Dedicar-se a léxicos especializados, como aquele ligado ao futebol, auxilia o professor quando ele precisa tratar de áreas mais específicas que são parte da cultura vinculada à língua que está ensinando, dando-lhe subsídios à comunicação e aproximando-o, juntamente com seus alunos, a um tema de interesse coletivo.

\section{A LF nos livros didáticos de italiano: tipos de exercícios e sugestões}

O estudo do léxico especializado permite o aprofundamento em um determinado tema dentro de um universo de discurso geral. Esse olhar mais específico abre caminho a uma compreensão setorizada durante o processo de aprendizado de uma LE e propicia a criação de raízes mais sólidas quando se aprende e apreende o léxico específico de uma área.

A pesquisa de que se fala neste artigo visou a contribuir para o enriquecimento do léxico do futebol em italiano LE, acreditando que seus aprendizes seriam capazes de se expressar melhor quando o assunto fosse esse esporte tão amado. Assim, a especificidade do universo do futebol será melhor desenvolvida quando encontrada em textos e unidades didáticas que se destinem a falar sobre ele, servindo de auxílio aos que estão desenvolvendo o italiano LE e aos que pouco ou nada entendem de futebol.

9 No original: Riflettere sulla didattica di una lingua significa, per un insegnante, ragionare in modo focalizzato e circostanziato sulla natura di determinati aspetti linguistici, sulle loro caratteristiche e sul loro comportamento all'interno di un discorso o di un testo. (Tradução das autoras) 
É possível verificar a LF em boa parte dos livros didáticos presentes no mercado editorial de italiano como segunda língua. Percebemos ainda que, além dos livros didáticos abordarem o tema do futebol italiano em suas seções de lazer e esportes mais praticados pelos italianos, a LF também está evidente em inteiras unidades didáticas que se utilizam dessa linguagem especificamente para ensinar diversos conteúdos gramaticais. Um exemplo é o que vemos na unidade 19 do livro Bravissimo. Trata-se de uma atividade com o léxico do futebol em que palavras são associadas a uma imagem (Figura 1). Balboni (1998, p. 133) classifica esse tipo de atividade didática como accoppiamento lingua-immagine e afirma que é uma ótima técnica para desenvolver a compreensão sem recorrer à produção.

Figura 1 - Atividade de associação língua-imagem

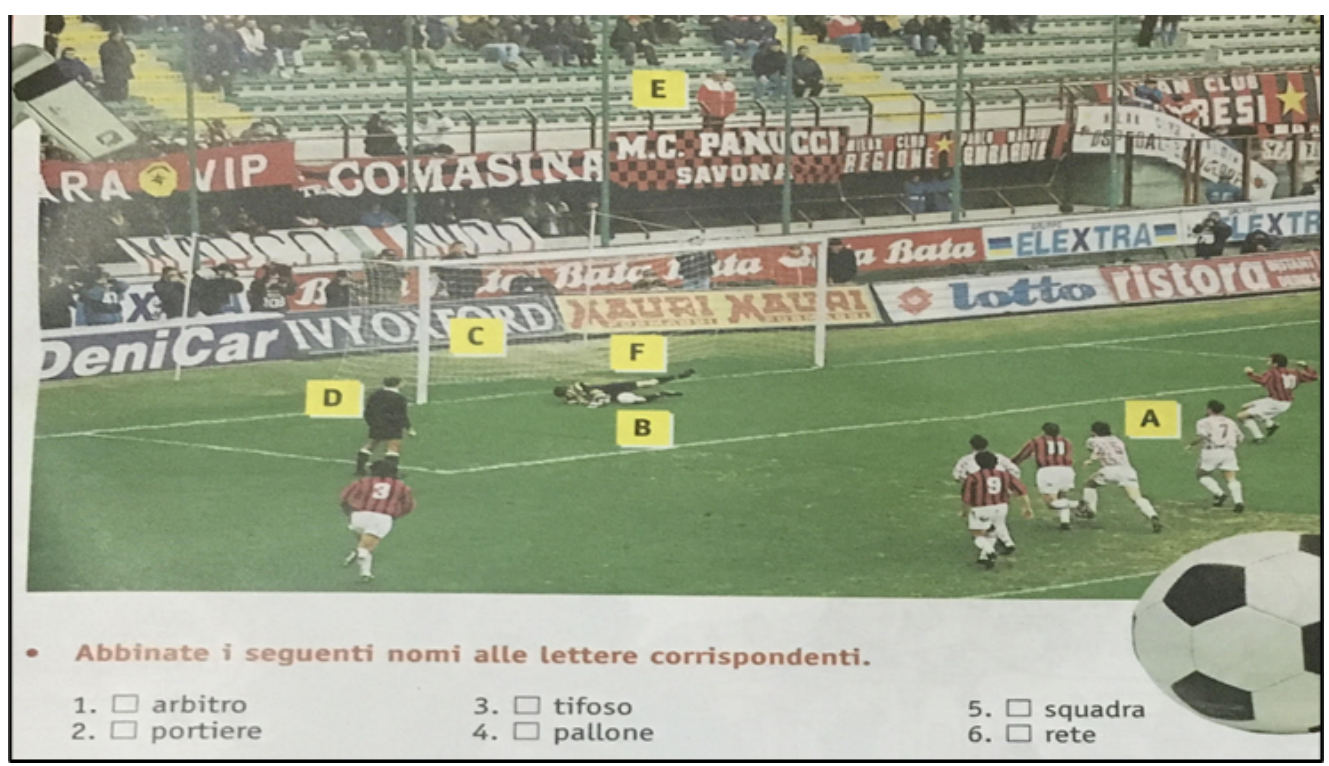

Fonte: Unità 19, Bravissimo (2000, p. 307)

Observa-se que o livro mostra a fotografia de um instante de uma partida de futebol. A atividade não implica uma produção oral ou escrita, mas requer do estudante um conhecimento prévio dos elementos que compõem a situação em campo. Sugerimos o uso do dicionário para auxiliá-lo a descobrir qual termo corresponde a cada elemento da fotografia, uma vez que os respectivos termos correspondentes em português não são semelhantes, com exceção de $a r$ bitro. Tanto dicionários bilíngues quanto monolíngues podem ser eficientes e eficazes para a compreensão dos termos em italiano, a depender de como são apresentadas as informações nos verbetes, como aponta a pesquisa de Zucchi (2010b). 
É interessante salientar que alguns livros didáticos apresentam os termos mais expressivos e/ou conhecidos da LF. É o que podemos verificar no material didático Un giorno in Italia 1. A atividade descrita a seguir (Figura 2) se vale também da associação língua-imagem, mas de uma maneira diversa:

Figura 2 - Atividade de associação língua-imagem e constelação

288 un giorno in italia . episodio 27

\section{Attività}

Prova a scrivere $i$ nomi in corrispondenza delle rispettive immagini.

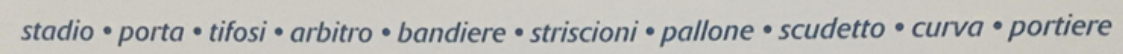
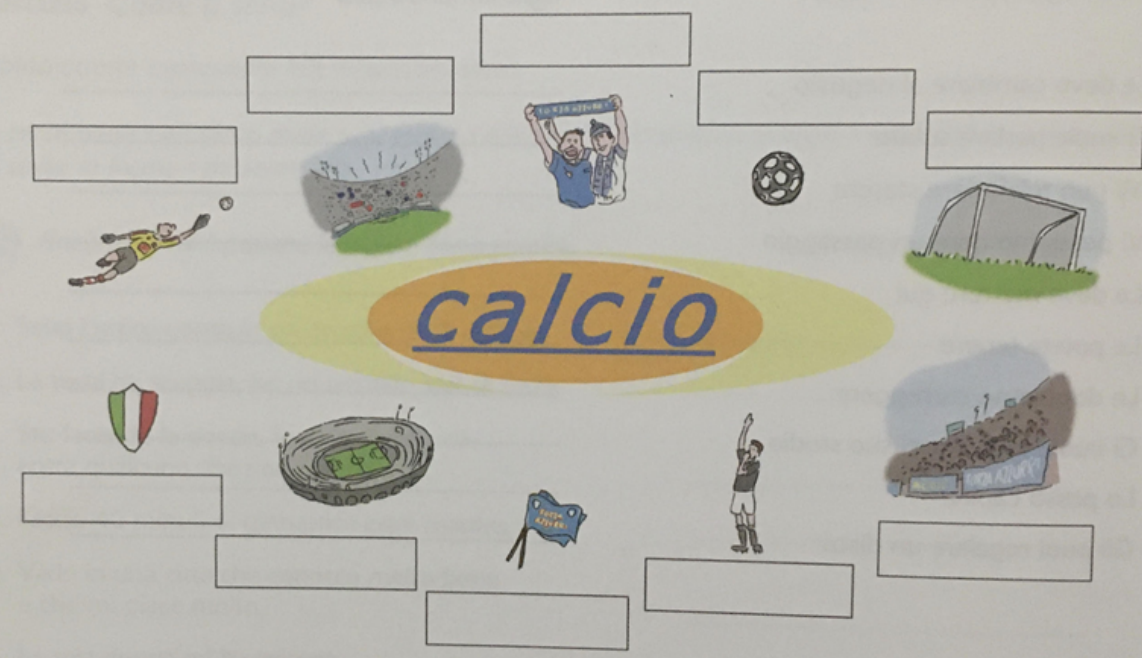

Fonte: Unità 27, Un giorno in italia 1 (2002, p. 288)

Essa forma é chamada por Balboni (1998, p. 145) de costellazione. O autor diz que o professor pode propor esse tipo de exercício colocando uma determinada palavra como o centro de um diagrama de tipo spidergram, isto é, com o formato de uma aranha cujas pernas são palavras associadas à que se encontra no centro e que podem, por sua vez, criar outras costellazioni. No caso desse exercício, a palavra central é calcio e as figuras representam o léxico relacionado 
ao futebol. Balboni afirma que este tipo de atividade é amplamente utilizado para desenvolver o léxico através dos campos semânticos. Seguindo o modelo de "constelação", sugerimos enriquecer esse exercício do livro Un giorno in Italia 1 com a inclusão dos verbos que se usam com cada um dos termos das imagens propostas, a fim de que seja possível formar frases. Por exemplo, fischiare com arbitro: l'arbitro fischia; vincere com scudetto: la squadra vince lo scudetto. Ampliando o exercício com os verbos adequados, o professor oferece ao aprendiz a noção de "colocação", conforme vimos no item 2 deste artigo.

No livro Nuovo progetto italiano 1 (libro dello studente), encontramos na Unidade $3 \mathrm{um}$ exercício (Figura 3) cuja proposta não tem como foco o léxico do futebol, como em outros livros, mas propõe um diálogo cujo tema central é ver um jogo na TV:

Figura 3 - Atividade de ordenação das falas de um diálogo

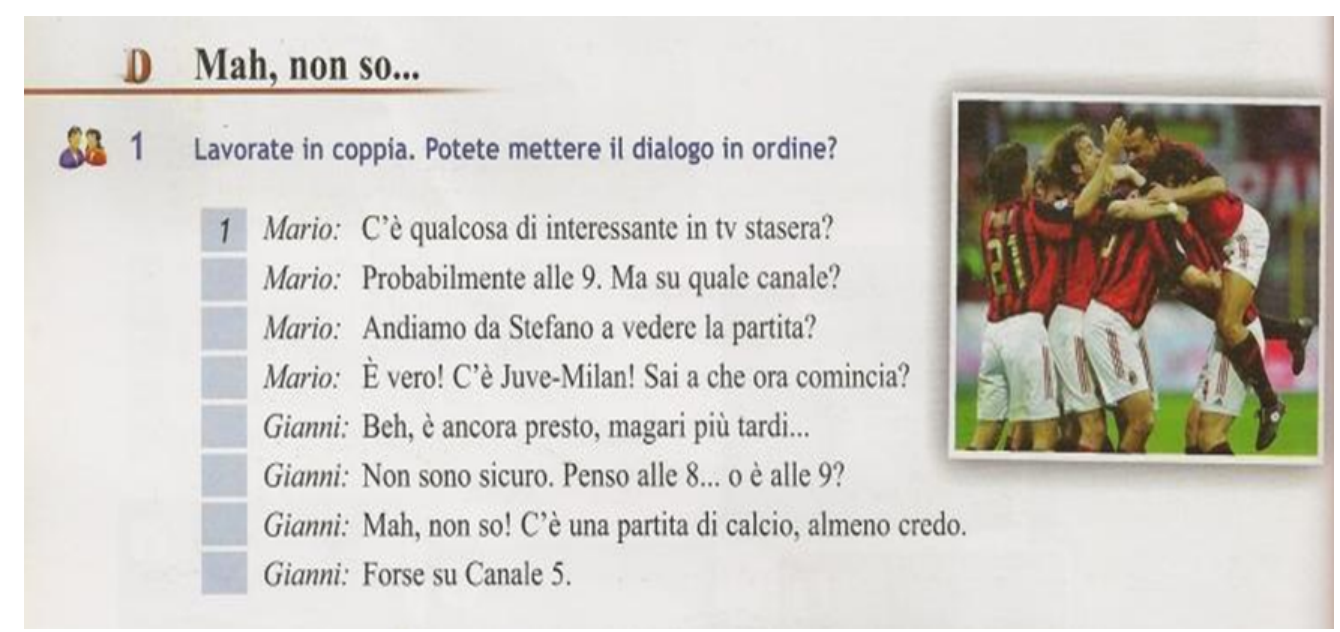

Fonte: Unità 3, Nuovo progetto italiano 1- libro dello studente (2009, p. 50)

A atividade propõe colocar em ordem as frases do diálogo. Balboni (1998, p. 157) denomina este tipo de exercício incastro delle battute di un dialogo, afirmando que há diferentes graus de dificuldade. Por exemplo, se as falas de um dos personagens já estão na ordem correta, a atividade tende a ser mais fácil. O autor afirma ainda que se trata de um exercício útil para reforçar as competências textuais e pragmáticas. Sugerimos o uso de dicionários para enriquecer a competência pragmática, com a consulta a um em que constem interjeições, como Il Nuovo De Mauro, disponível on-line ${ }^{10}$, onde o aprendiz pode ampliar o conhecimento sobre alguma interjeição presente no diálogo.

10 https://dizionario.internazionale.it/parola/mah 
O exercício do livro L'italiano per amico (2007, p. 45) apresenta, também na forma de associação imagem-palavra como nos exercícios citados anteriormente, termos específicos presentes num jogo, como "cartão" e "faixa", respectivamente em italiano schedina e striscione (Figura 4):

\section{Figura 4 - Atividade de associação língua-imagem}

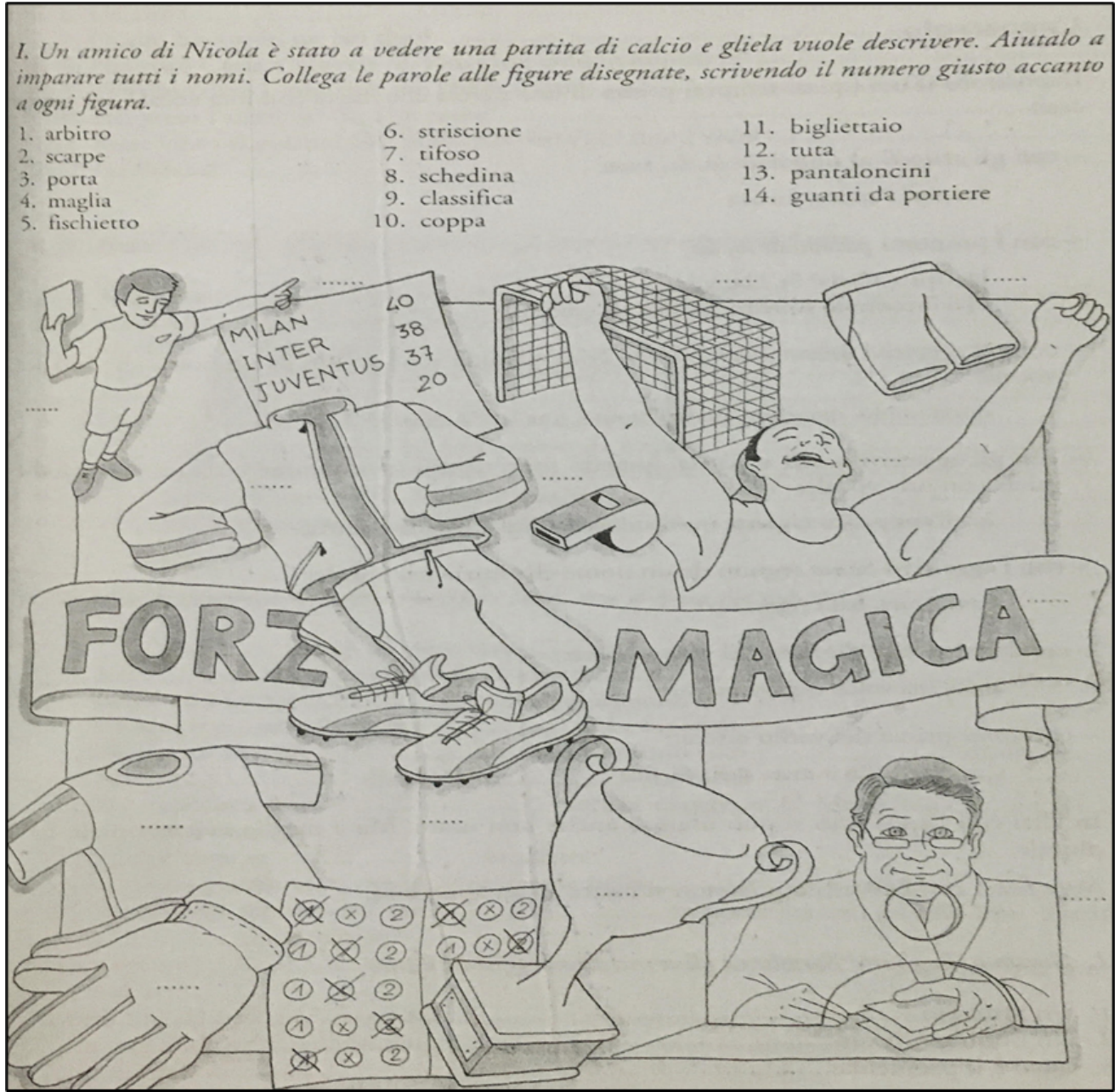

Fonte: Unità 3, L'italiano per amico (2007, p. 45) 


\section{Procedimentos metodológicos: seleção, análise e resultados obtidos}

Tendo sido decidido que o corpus de estudo seria composto por livros didáticos de italiano LE, foram estabelecidos dois critérios para a seleção: período de publicação e utilização comprovada em cursos de idiomas. Assim, foram analisados 21 livros publicados num período de vinte anos (1998-2018), adotados como material didático de alguns cursos de italiano do Estado do Rio de Janeiro" ${ }^{11}$. A LF foi detectada em 18 deles:

- Arrivederci 2;

- Arrivederci! 1;

- Bravissimo;

- Chiaro A1;

- Contatto 1;

- L'italiano per amico (Comunità di Sant'Egidio)

- Linea Diretta 2;

- Lingua e Civiltà D'Italia

- Magari!

- Nuovo Progetto Italiano 1 (libro dello studente);

- Nuovo Progetto Italiano 1 (quaderno degli esercizi);

- Nuovo Progetto Italiano 2 (libro dello studente);

- Nuovo Progetto Italiano 2 (quaderno degli esercizi);

- Nuovo Progetto Italiano 3 (libro dello studente);

- Nuovo Progetto Italiano 3 (quaderno degli esercizi);

- Rete! 2;

- Un giorno in Italia 1;

- Via del Corso A1;

Após a seleção dos livros didáticos, o primeiro passo foi construir tabelas onde foram inseridas informações sobre os livros e sobre a presença dos termos futebolísticos, com o propósito de ter um instrumento de comparação, de realizar análises quantitativas e de dispor mais facilmente do elenco dos termos e fraseologismos da LF presentes nos livros didáticos. Nessas tabelas, as informações contidas foram:

1. Autor e Editora (para atestar com precisão as referências de cada livro);

2. Edição e Nível (ano de publicação e a apresentação do nível de acordo com o Quadro Comum Europeu de Referência - QCER: A1 e A2 (nível elementar), B1 e B2 (nível intermediário), C1 e C2 (nível avançado));

3. Página(s) onde se encontra a LF, auxiliando em uma busca rápida;

11 Os livros foram adotados pelas seguintes escolas: Acemakers Idiomas, Clube Naval - sede social, Excellence + Brasil Idiomas, High School Idiomas, Instituto de Aprendizagem - I.AP, Istituto Italiano di Cultura, Licom (Línguas para comunidades - UERJ), Associação ítalo-brasileira - ACIB e ASW Idiomas. 
4. Presença e Ausência da LF (se há presença ou pouca presença da LF). Quanto a esse critério, decidimos que, para ser classificado como "Presença", era necessário ter um total de até vinte registros de termos e fraseologismos, e "Pouca Presença", menos de vinte registros);

5. Unidade(s) e página(s) (para apontar em quais unidades e páginas estão a LF);

6. Tempo libero e Sport (para indicar se a LF se encontra na seção Tempo Libero que quase todos os livros didáticos possuem ou na seção Sport, em que se fala dos esportes mais praticados pelos italianos);

7. Descrição da atividade (se possui imagem, se é voltada para o léxico, fraseologismo, para a compreensão oral, leitura, conversação, produção textual ou oral).

Para cada um dos 18 livros didáticos foi construída uma tabela. Exemplificamos os resultados obtidos com a Tabela 1, em que constam os dados do Nuovo Progetto Italiano 1 (quaderno degli esercizi):

Tabela 1 - Dados quantitativos e informações

\section{APÊNDICE B}

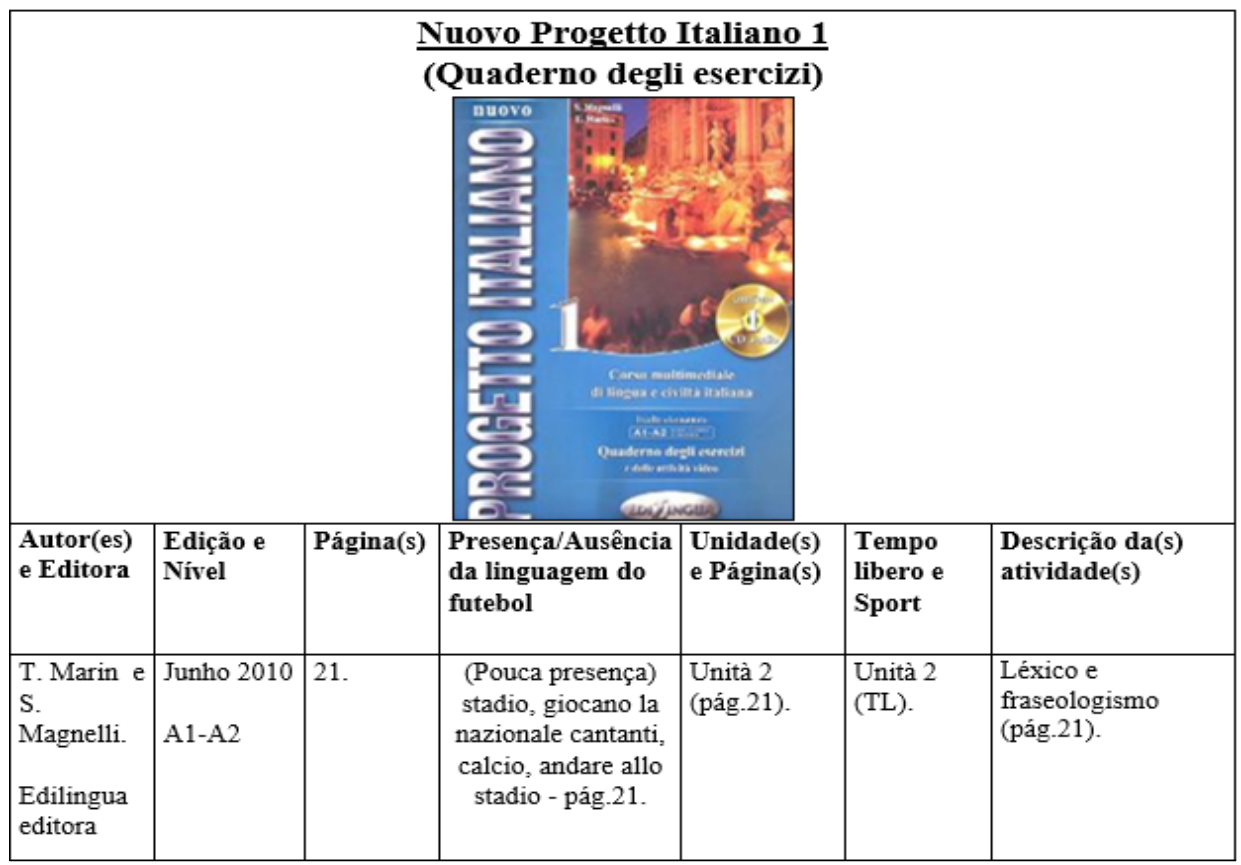

Fonte: Dados de pesquisa de Martins (2020) 
Destacamos que os nomes dados às descrições dos tipos de atividades não foram aleatórios, mas foram assim definidos pois correspondiam à maneira em que as atividades didáticas eram apresentadas nos livros de italiano LE, sendo uma exceção a referência ao fraseologismo. Este, por sua vez, foi incluído entre nossas categorias para indicar que, naquela atividade específica, ocorria um fraseologismo.

Por meio da análise das tabelas, identificamos quantitativamente a presença da LF em atividades nos livros classificados conforme os níveis do QECR, na seguinte proporção (Tabela 2):

Tabela 2 - Ocorrências da LF em atividades de livros - nível QECR

\begin{tabular}{|c|c|}
\hline Nível A1 & 8 \\
\hline Nível A2 & 6 \\
\hline Nível B1 & 9 \\
\hline Nível B2 & 11 \\
\hline Nível C1 & 4 \\
\hline Nível C2 & 0 \\
\hline
\end{tabular}

Fonte: Dados da pesquisa de Martins 1 (2020)

Concluímos, com base nesses dados, que os livros didáticos de níveis ${ }^{12} \mathrm{~A} 1, \mathrm{~B} 1$ e B2 foram os que mais apresentaram a LF, com um total de 28 ocorrências, tendo os níveis A2, C1 e C2 as menores incidências, isto é, dez referências.

Foram extraídos das 18 tabelas um total de 451 registros de termos e fraseologismos, tendo sido encontradas, para cada livro didático, as seguintes quantidades expressas em números (Tabela 3):

Tabela 3 - Número de termos e fraseologismos por livro didático

\begin{tabular}{|l|c|}
\hline Arrivederci! 1 & 8 \\
\hline Arrivederci! 2 & 16 \\
\hline Bravissimo & 158 \\
\hline Chiaro A1 & 2 \\
\hline Contatto 1 & 5 \\
\hline L'italiano per amico (Comunità di Sant'Egidio) & 152 \\
\hline
\end{tabular}

$\overline{12}$ Quando o livro indicava abrangência em dois níveis, por exemplo B2-C1, foi considerado somente o primeiro nível. 


\begin{tabular}{|l|c|}
\hline Linea Diretta 2 & 28 \\
\hline Lingua e Civiltà D'Italia & 6 \\
\hline Magari! & 20 \\
\hline Nuovo Progetto Italiano 1 (libro dello studente) & 19 \\
\hline Nuovo Progetto Italiano 1 (quaderno degli esercizi) & 3 \\
\hline Nuovo Progetto Italiano 2 (libro dello studente) & 29 \\
\hline Nuovo Progetto Italiano 2 (quaderno degli esercizi) & 2 \\
\hline Nuovo Progetto Italiano 3 (libro dello studente) & 91 \\
\hline Nuovo Progetto Italiano 3 (quaderno degli esercizi) & 33 \\
\hline Rete! 2 & 1 \\
\hline Un giorno in Italia 1 & 14 \\
\hline Via del Corso A1 & 24 \\
\hline
\end{tabular}

Fonte: Dados da pesquisa de Martins (2020)

A partir dessa análise, observamos que somente oito dos livros didáticos apresentaram mais de 20 registros e dez expressaram menos de 20. Apresentamos, então, os dados em ordem decrescente do número de termos da LF nos livros didáticos (Tabela 4):

Tabela 4 - Número de termos e fraseologismos por livro didático em ordem decrescente

\begin{tabular}{|l|l|}
\hline Bravissimo & 158 \\
\hline L'italiano per amico (Comunità di Sant'Egidio) & 152 \\
\hline Nuovo Progetto Italiano 3 (libro dello studente) & 91 \\
\hline Nuovo Progetto Italiano 3 (quaderno degli esercizi) & 33 \\
\hline Nuovo Progetto Italiano 2 (libro dello studente) & 29 \\
\hline Linea Diretta 2 & 28 \\
\hline Via del Corso A1 & 24 \\
\hline Magari! & 20 \\
\hline Nuovo Progetto Italiano 1 (libro dello studente) & 19 \\
\hline Arrivederci! 2 & 16 \\
\hline Un giorno in Italia 1 & 14 \\
\hline Arrivederci! 1 & 8 \\
\hline Lingua e Civiltà D'Italia & 6 \\
\hline
\end{tabular}




\begin{tabular}{|l|l|}
\hline Contatto 1 & 5 \\
\hline Nuovo Progetto Italiano 1 (quaderno degli esercizi) & 3 \\
\hline Chiaro A1 & 2 \\
\hline Nuovo Progetto Italiano 2 (quaderno degli esercizi) & 2 \\
\hline Rete! 2 & 1 \\
\hline
\end{tabular}

Fonte: Dados da pesquisa de Martins (2020)

É expressiva a diferença entre os três primeiros e os demais livros didáticos. Podemos afirmar que, se o interesse do aluno for aprender a terminologia do futebol, poderá encontrar mais exemplos de textos e atividades didáticas com esse enfoque nos livros Bravissimo, L'italiano per amico (Comunità di Sant'Egidio) e Nuovo Progetto Italiano 3 (libro dello studente).

Com a informação sobre quais unidades continham a LF (v. Tabela 1), verificamos que praticamente todos os livros apresentam referências ao futebol nas unidades dedicadas aos temas Sport e Tempo libero.

\section{Linhas gerais da organização do glossário}

Após a coleta dos 451 registros a partir dos dezoito livros didáticos, organizamos os termos e os fraseologismos encontrados em ordem alfabética, classificando os termos em gênero (masculino e feminino), substantivo invariável, número (singular e plural), verbo (transitivo, intransitivo e reflexivo), adjetivo e advérbio. Incluímos esclarecimentos quanto à etimologia, no caso de empréstimos, e informações quanto à convencionalidade, no caso de termos usados somente no plural.

Para uma classificação precisa, quando houve dúvidas, recorremos aos dicionários Il Sabatini Coletti (2006) e Devoto-Oli (2011) para não incorrermos em erros quanto à categorização dos termos.

Destacamos que o glossário italiano da terminologia do futebol para fins didáticos é monolíngue e, por isso, optou-se por não fazer as correspondências dos termos e expressões em língua portuguesa, já que a pesquisa não teve seu foco voltado para a tradução. De fato, para fazer um glossário em versão bilíngue, seria necessário fazer uma pesquisa com aporte teórico sobre tradução e com um corpus também em português sobre futebol.

Para as escolhas relativas à organização do glossário especializado, nos pautamos nos estudos de Bevilacqua $(1998 ; 2005)$, citados no item 2 deste artigo. Para formar a nomenclatura, isto é, a lista de palavras como entradas do glossário, colocamos em ordem alfabética termos simples (ex.: calcio), unidades terminológicas poliléxicas (ala sinistra) e o termo nucleador-base das unidades fraseológicas especializadas (fare il tifo).

O segundo passo foi colocar os exemplos de uso extraídos dos livros didáticos logo após as entradas. Já a disposição da ordem dos exemplos foi escolhida de acordo com a maior pos- 
sibilidade de oferecer compreensão ao significado dos termos e fraseologismos. Foi indicada a fonte de cada um dos exemplos de uso e, para isso, foram criadas siglas para indicar de quais livros didáticos e páginas de onde foram extraídos os exemplos. Como exemplo de verbete apresentamos:

\section{palestra (s.f.sing.)}

C'è chi va in palestra non per mantenersi in forma, ma solo per conoscere gente... (NPI3-LS, p. 72).

Entre parênteses, apresentamos a fonte, a sigla referente ao nome do livro didático. No caso do exemplo que acabamos de apresentar, a sigla NPI3-LS corresponde ao livro Nuovo Progetto Italiano 3 - Libro dello studente, página 72. É importante salientar ainda que as entradas e suas classificações são evidenciadas em negrito. Já os exemplos de uso são apresentados em itálico, separados por ponto e vírgula, enquanto os termos e fraseologismos neles contidos são sublinhados para facilitar a consulta. Algumas das entradas oferecem muitos exemplos, como no caso reportado a seguir:

\section{pallone (s.m.sing.)}

Nel gioco di calcio sono ventidue calciatori correndo indietro ad un pallone. (UGI1, pag.288); Il pallone solo il portiere può toccarlo con le mani. (BRVS-E.I, pag.307); Questa possibilità fu concessa otto anni più tardi al solo portiere, limitatamente a quando il pallone si trovava nella sua area. (BRVS-E.I, pag.321); Nessuno di loro poteva però toccare il pallone con le mani. (BRVS-E.I, pag.321); George ha toccato il pallone con la mano. (IPA, pag.41); João, con lieve tiro, fece passare il pallone sopra il corpo del portiere mentre quello si tuffava; ma... (IPA-I, pag.50); Tifoso: "Se il pallone non avesse colpito il palo, sarebbe stato gol, e la mia squadra avrebbe vinto!" (LCI-E.I, pág.182); Negozi, bar e aziende di Rio sponsorizzano le squadre pagando le magliette, pallone e, qualche volta, il biglietto dell'autobus, per ritornare dalla spiaggia a casa, dopo la partita. (IPA-I, pag.48) João gioca a pallone sulla sabbia nella spiaggia di Copacabana. (IPA-I, pag.40); Italia = calcio? È vero che il pallone è lo sport più amato, tuttavia solo alcuni lo praticano. (ARR-A2, pag.14); Come mai, visto che a pallone non sei mai stato bravo, ora sei così tifoso del calcio. (IPA, pag.38); Lei era diventata sempre insofferente delle chiassose riunioni con gli amici in casa nostra, davanti alla tv, dei commenti prima, durante e dopo le partite, degli slanci e degli entusiasmi che, secondo lei, avevo solo per il pallone. (NPI3-LS, pag.70); Qui non conosco quasi nessuno, dopo la scuola sto sempre chiuso in casa a guardare la tv, perché non c'è nemmeno un cortile per giocare a pallone. (CNT1, pag.188); Nei cortili dei condomini non si può giocare a pallone, non si può andare in bicicletta, non si può andare sui pattini, non ci si può rincorrere perché si crea schiamazzo. (LD2, pag.81); Giocare a pallone è un'attività molto divertente e praticata dai bambini. (BRVS-E.I, pag.70); Tutti i ragazzi di Rio, quando arriva il tramonto, si ritrovano 
sulla sabbia, ancora tiepida per il grande caldo della giornata, per giocare a pallone. Ma non si tratta di dare quattro calci al pallone prima di cena. Le partite, qui, sono un avvenimento serio, serissimo: ogni ragazzo è inserito in una squadra e ciascuna squadra ha uno sponsor locale. (IPA-I, pag.48); Giocare a pallone mi piace, anche se non sono mai stato molto bravo. (IPA-I, pag.51); Pensa che, quando ero piccolo, giocavo a pallone tutti i pomeriggi, sono casa, assieme ad altri sei amici miei. (IPA-I, pag.38); La fede nel dio Pallone ha la sua massima espressione nella Nazionale Italia di Calcio. Questa divinità è l'unità che sa far dimenticare le miserie dell'esistenza, una divinità così potente da essere in grado di far abbracciare, dopo un goal, persone di idee politiche opposte. Questi sono i veri miracoli!!! (NPI3-QS, pag.29) pallone d'oro. Il calcio italiano è il più rappresentato nella lista dei 50 candidati al Pallone d'Oro, pubblicata da France Football. In elenco ci sono infatti ben otto giocatori di casa. (ARR-A2, p. 14)

Como se vê, o termo pallone, bola de futebol, aparece em muitos dos livros didáticos. Pelos exemplos, nota-se que na maioria das vezes o enunciado faz referência ao contexto do futebol, mas algumas frases deixam claro o objetivo gramatical implícito, como no exemplo extraído do livro Lingua e Civiltà D'Italia (LCI-E.I, pág.182), em que é apresentado um diálogo no qual é empregado o período hipotético.

Em relação às palavras de origem não italiana, lembramos que o futebol foi criado pelos ingleses, como visto no item $1 \mathrm{e}$, por isso, é comum que tenhamos um repertório lexical em inglês. Na pesquisa, dentre os 451 registros selecionados, encontramos quatro termos e uma colocação na língua inglesa: club, derby, goal, sport e a colocação Champions League, que dá nome a um campeonato. Concluímos, assim, que foram incluídos alguns empréstimos nos livros didáticos, mas poucos.

No alfabeto italiano, não há a letra "J", no entanto, ela é presente em alguns nomes de origem latina, como para se referir ao time de futebol da cidade de Turim, Juventus, e seus torcedores, os juventini. A pronúncia da letra "J" pelos italianos é como "i".

Foram incluídos na nomenclatura quatro verbos, que classificamos como: giocare (verbo intransitivo), segnare (verbo transitivo), tifare (verbo intransitivo) e allenarsi (verbo reflexivo) ${ }^{13}$. São verbos que fazem parte do universo futebolístico.

Quanto à convencionalidade ${ }^{14}$ (Tagnin, 2013), evidenciamos os seguintes termos: pantaloncini e ultras (este último de origem francesa), que são sempre empregados no plural e não no singular.

Para indicar remissiva de um termo, utilizamos o seguinte símbolo da seta direcionada para a direita $(\rightarrow)$, como no caso de palla $\rightarrow$ pallone.

13 O verbo allenarsi pode ser considerado como verbo pronominal por alguns dicionaristas, mas como nos baseamos nos dicionários Devoto-Oli (2011) e Il Sabatini Coletti (2006) para o desenvolvimento desta pesquisa, optamos por deixar a classificação de verbo reflexivo.

$14 \quad$ Entende-se por aquilo que se convencionou dizer e por isso foi aceito pelos falantes. Segundo Tagnin (2013), a convencionalidade pode ocorrer nos níveis Pragmático, Semântico e Sintático. 
Essas foram as linhas gerais da elaboração do glossário, cujos insumos foram obtidos por meio dos procedimentos metodológicos descritos na pesquisa de Martins (2020).

\section{Considerações finais}

Quando estudamos léxicos especializados de uma determinada língua, estamos colhendo uma parte específica daquela língua e de sua cultura. Esta foi a proposta deste trabalho, ou seja, destacar a importância da LF para fins didáticos e como essa forma de se expressar é apresentada nos livros didáticos, especialmente em exercícios.

A pesquisa fez um recorte sobre a história do futebol e a relevância desse esporte no Brasil e na Itália, tentando demonstrar não somente o interesse que esses povos têm pelas atividades esportivas, mas como a expressão linguística relativa a ele se apresenta como uma linguagem de especialidade presente em livros didáticos de italiano LE.

Discorremos sobre a importância das diversas áreas das Ciências do Léxico e seus respectivos objetos de estudo: Lexicologia, léxico; Lexicografia, obras lexicográficas; Terminologia, termo; Terminografia, obras lexicográficas especializadas ou técnicas e Fraseologia, fraseologismos e unidades fraseológicas especializadas - como base aos nossos estudos para compormos um glossário italiano da terminologia do futebol para fins didáticos.

A metodologia utilizada para a elaboração do glossário consistiu na seleção de livros didáticos publicados em um período de vinte anos, de 1998 a 2018, em que era presente o tema futebol; na organização das informações extraídas dos livros em tabelas; na análise dos termos e fraseologismos nos contextos; na seleção das entradas; na criação dos verbetes com a classificação das entradas e exemplos extraídos dos livros didáticos.

Observamos que alguns termos eram presentes na maioria dos livros, como calcio, pallone, partita e squadra, que apresentaram as maiores quantidades ocorrências. Em relação ao número de atividades que continham referências ao futebol, constatamos que havia um índice maior nos livros destinados aos níveis B1e B2 do QCER (Tabela 2) e que o livro didático com maior número de termos e fraseologismo dessa área é Bravíssimo (Tabela 4).

Verificamos também que a LF nos livros didáticos se encontrava nas seções destinadas ao tema "tempo livre" ou "lazer" dos italianos (Tempo libero), ou naquelas sobre os esportes mais praticados no país (Sport).

Acreditamos que, ao atingirmos 451 registros de presença da LF nos livros didáticos de italiano LE, respondemos a um de nossos objetivos, que era aquele de demonstrar que, embora seja uma linguagem especializada, ela pode ser estudada e ensinada para auxiliar na produção e compreensão, tanto escrita como oral, em todos os níveis de aprendizagem, seja básico, intermediário ou avançado.

Neste artigo, além de discorrermos sobre as Ciências do Léxico, especialmente a Lexicografia, a Terminologia e a Fraseologia, como já indicamos anteriormente, falamos sobre sua importância no ensino de línguas e demos exemplos e sugestões de uso de dicionário em exer- 
cícios oferecidos por livros didáticos.

Trouxemos, ademais, alguns exemplos de atividades dos livros didáticos nos quais era presente a LF, classificando-as segundo Balboni (1998), e sugerimos outras atividades como meio de continuar a desenvolver o tema. Apresentamos dois exemplos de verbete (partita e pallone) e discorremos sobre alguns dados resultantes da análise da LF nos livros didáticos e da elaboração do glossário.

Como desdobramentos futuros, a partir do corpus apresentado, será possível elaborar um dicionário bilíngue no par italiano-português brasileiro, incluindo um corpus sobre futebol em português, e proporcionar um instrumento de auxílio a professores e aprendizes para o entendimento do uso dessa forma especializada de expressão linguística e cultural.

\section{Referências}

ALMEIDA, G. M. B. O percurso da Terminologia: de atividade prática à Consolidação de uma disciplina autônoma. Tradterm, v. 9, 2003, p. 211-222. DOI: 10.11606/issn.2317-9511.tradterm.2003.49087

ANTUNES, I. Língua, texto e ensino: outra escola possível. São Paulo: Parábola Editorial, 2009.

AUBERT, F. H. Introdução à metodologia da pesquisa terminológica bilíngue. Cadernos de terminologia 2. São Paulo: Humanitas, 2001.

AUTELLI, E. L'insegnamento dei fraseologismi nell'italiano come lingua seconda: proposta di un modello didattico misto. DILLE. Università di Calabria, 2015, 171-180.

BALBONI, P. Didattica dell'italiano a stranieri. Università per Stranieri di Siena. Roma: Bonacci, 1994.

BALBONI, P. Tecniche didattiche per l'educazione linguistica. Italiano, lingue straniere, lingue classiche. Torino: Utet Libreria, 1998.

BEVILACQUA, C. R. Unidades Fraseológicas Especializadas: Novas perspectivas para sua identificação e tratamento. Organon - Revista do Instituto de Letras da UFRGS, v. 12, n 26, 1998, p. 1-8. DOI: https://doi.org/10.22456/2238-8915.29562

BEVILACQUA, C. R. Unidades Fraseológicas Especializadas: estado da questão em relação a sua definição, denominação e critérios de seleção. TradTerm, 11, 2005, p. 237-253. DOI: https://doi. org/10.11606/issn.2317-9511.tradterm.2005.49689

BIDERMAN, M. T. C. O Léxico. In: ISQUERDO, A. N.; OLIVEIRA, A. M. P. P. (orgs.). As ciências do léxico. Lexicologia, lexicografia e terminologia. 2 ed. Campo Grande: UFMS, 2001, p.13-22

BLAIS, E. Le phraséologisme. Une hypothése de travail. Terminologies Nouvelles. RINT, n. 10, 1993, p. 51-53.

COLETTI, V.; SABATINI, F. Dizionario Il Sabatini Coletti. Rizzoli-Larousse, 2006.

CORACINI, M. J. R. F. (org.). Interpretação, autoria e legitimação do livro didático: língua materna e língua estrangeira. Campinas: Pontes, 1999.

DEVOTO, G.; OLI, G. C. Il Devoto-Oli. Vocabolario della lingua italiana. Milano: Le Monnier, 2011.

FRANGIOTTI, G. A. A sociolinguística no ensino de línguas: a variação diastrática em manuais didáticos de italiano. Revista de Italianistica, 38, 2019, p. 17-38. https://doi.org/10.11606/issn.2238-8281. v0i38p17-38 
GALLI, P. Il linguaggio del calcio un'analisi multiprospettiva. Tesina. Università degli studi di Bergamo, Bergamo, 157 f., 2011. Disponível em: https://www.alleniamo.com/archivi.alleniamo.com/autori/ galli.htm

KRIEGER, M. G.; FINATTO, M. J. B. Introdução à Terminologia - teoria \& prática. São Paulo: Contexto, 2004.

MARTINS, B. A. D. A terminologia do futebol em livros de italiano língua estrangeira: proposta de glossário para fins didáticos. Dissertação. Universidade de São Paulo, São Paulo, 200 f., 2020. Disponível em: https://www.teses.usp.br/teses/disponiveis/8/8148/tde-22062020-205158/pt-br.php

MATTOS, A. Enciclopédia do Futebol Brasileiro e Mundial. Belo Horizonte: Editora Leitura, 2002.

QUEIROZ, J.M. Vocabulário do futebol na mídia impressa: o glossário da bola. Tese. Universidade Estadual Paulista, São Paulo, 954 f., 2005.

TAGNIN, S.E.O. Convencionalidade e Produção de texto: Um dicionário de colocações verbais inglês/português - português/inglês. Tese (Livre Docência). Universidade de São Paulo, São Paulo, 199 f., 1998.

TAGNIN, S.E.O. O jeito que a gente diz. Barueri: DISAL Editora, 2013.

ZUCCHI, A.M.T. Dicionário monolíngue no ensino de língua estrangeira: uma experiência de uso. In: ISQUERDO, A. N.; FINATTO, M. J. B. (orgs.). As Ciências do Léxico-Lexicologia, Lexicografia, Terminologia. Vol. IV. 1 ed. Campo Grande: Editora UFMS/UFRGS, 2010a, p. 255-268.

ZUCCHI, A.M.T. O dicionário nos estudos de línguas estrangeiras: os efeitos de seu uso na compreensão escrita em italiano. 2010b. Tese. Universidade de São Paulo, São Paulo, 284 f., 2010. Disponível acesso aos resultados pela citação em: WELKER, H.A. Dictionary Use - A General Survey of Empirical Studies em https://hawelk.wixsite.com/hawelker/livros-publicados

\section{Corpus de estudo: livros didáticos}

AMORINI, E.; MAZZETTI, A. Lingua e Civiltà D'Italia. Firenze: Le Monnier editora, 1998.

BALBONI, P.E.; MEZZADRI, M. Rete! 2. Corso multimediale d'italiano per stranieri. Perugia: Guerra, 2001.

BIDETTI, A; DOMINICI, M; PICCOLO, L. Nuovo progetto italiano 3. Quaderno degli esercizi. Roma: Edilingua, 2008.

CHIAPPINI, L; DE FILIPPO, N. Un giorno in Italia 1. Corso di italiano per stranieri. Roma: Bonacci, 2002.

COLOMBO, F; DE LUCA, P.; FARACI, C. Arrivederci! 1. Corso multimediale di italiano per stranieri. Roma: Edilingua, 2011.

COLOMBO, F.; DE LUCA, P.; FARACI, C. Arrivederci 2. Corso multimediale di italiano per stranieri. Roma: Edilingua, 2011.

CONFORTI, C.; CUSIMADO, L. Linea Diretta 2. Corso di italiano a livello medio. Perugia: Guerra, 2004.

COSTA, R. B.; GHEZZI, C.; PIANTONI, M. Contatto. Corso di italiano per stranieri. Torino: Loescher, 2005.

DE GIULI, A; GUASTALLA, C; NADDEO, C. M. Magari. Corso di lingua e cultura italiana. Firenze: Alma, 2008.

DE SAVORGNANI, G.; BERGERO, B. Chiaro! Corso di italiano. Libro dello studente ed eserciziario. Firenze, Alma, 2010. 
DIADORI, P.; MARIN, T. Via del corso. Corso di italiano per stranieri. Roma: Edilingua, 2017.

KATERINOV, K.; KATERINOV, M. C. B. Bravissimo. Milano: Edizioni Scolastiche Bruno Mondadori, 2000.

MAGNELLI, S.; MARIN, T. Nuovo progetto italiano 2. Libro dello studente. Roma: Edilingua, 2009.

MAGNELLI, S.; MARIN, T.; RUGGIERI, L. Nuovo progetto italiano 2. Quaderno degli esercizi. Roma: Edilingua, 2013.

MARIN, T. Nuovo progetto italiano 1. Libro dello studente. Roma: Edilingua, 2009.

MARIN, T. Nuovo progetto italiano 1. Quaderno degli esercizi. Roma: Edilingua, 2013.

MARIN, T. Nuovo progetto italiano 3. Libro dello studente. Roma: Edilingua, 2008.

MARTANO, V. et al. L'italiano per amico. Comunità di Sant'Egidio. Brescia: La Scuola, 2007.

Recebido em: 11/04/2021 (versão atualizada: 25/06/2021)

Aprovado em: 27/07/2021 